\title{
Relationship among Anthropometric, Body Composition and Physical Fitness of Basketball Skill Performance: A Study of Ethiopian University Players
}

\author{
Tariku Assefa and Ashok Kumar
}

\begin{abstract}
Aim: the present study was to identify the relationships among anthropometric, body composition and physical fitness with basketball skill performance of Ethiopian inter University male basketball players. Method: two hundred $(\mathrm{N}=200)$ men basketball players selected by simple random sampling technique from Ethiopian inter University basketball Tournament. To achieve the objectives of the study six Anthropometric variables, eight Body composition variables and six physical fitness variables were included as independent variables and one dependent variable basketball skill performance which was assessed by AAHPERD basketball skill test (Accuracy speed passing, control dribbling, defensive movement and speed spot shooting).It was aggregation made by using principal component analysis to reduce correlated variable in to one. Results: Person's product moment correlation was used as a statistical tool. The result showed that Anthropometric variables i.e. weight, height, body mass index, arm length, Palme length and leg length were found to possess positive and significant $(\mathrm{p}<0.05)$ correlation with the basketball skill performance at 0.01 , body composition variables i.e. Biceps skin fold, triceps skin fold, subscapular skin fold, suprailiac skin fold, percent of body fat andfat weight were found to possess negative and significant $(\mathrm{p}<0.01)$ correlation with the basketball skill performance at 0.01 , body density and lean body mass measurements were found to possess positive and significant $(\mathrm{p}<$ 0.01 ) correlation with the basketball skill performance at 0.01 and physical fitness variables i.e.Sit and reach ,sergeant jump, Harvard step test and hand grip dynamometer for strength were found to possess positive and significant $(\mathrm{p}<0.01)$ correlation with the basketball skill performance at 0.01 and 50 meter dash and SEMO agility were found to possess negative and significant $(\mathrm{p}<$ 0.01 ) correlation with the basketball skill performance at 0.01 . Conclusion: Hence, it can be concluded from the findings of the present study that Anthropometric, Body composition and physical fitness variables contribute significant in basketball skill performance.
\end{abstract}

Tariku Assefa

$\mathrm{Ph}$.D. Student

Department of Sports Science

Punjabi University, Patiala, India

E mail: tarikuass@gmail.com

Ashok Kumar

Associate Professor

Department of Sports Science

Punjabi University, Patiala, India
Key Words: Anthropometric, Basketball performance, Body composition

DOI: $10.18376 /$ jesp/2018/v14/i1/111293 


\section{INTRODUCTION}

Basketball is a type of ball game, it can be performed in high-intensity with the demand of physical contact, high speed and constant jumps (both to offense and to defend) and changes (Paiva and Cesar, 2005). Basketball needs a person to be physically fit in nature as well as technical and tactical abilities for optimal performance (Hoffman et al., 1999). In a very broad sense physical fitness is, determined by the individual's capacity for optional work and motor and sport performance (Astrand and Rodahl, 1986). However, during competition the physical fitness of a player can be a decisive determinant of success (Smekal et al., 2001). A high level of speed, power, explosiveness and agility are needed for Basketball players (Boone \&Bourgois, 2013). Because of those movements are frequently performed by players during different positions (blocking, shooting and rebounding) maneuvers vertical jump and sprint exercise are the essential for motor components of basketball game (McInnes et al., 1995; Adelkerimet al., 2007). One of a factor affecting performance in basketball has been described by jump power (Greene et al., 1998). Basketball is one of the complex technical team games and differences in performance between players of different region and varying ability standard needs the implementation of variety of different abilities (Angyan, et al., 2003). Team games were sports where size, shape, body composition and fitness all play animportant part in providing distinct advantage for specific playing positions particularly at thehigher level, where there is a high degree of player specialization (Dey, Kar \& Debray, 2010). The objective of the present study was to identify the relationships among anthropometric, body composition and physical fitness with basketball skill performance of Ethiopian inter University male basketball players

\section{MATERIAL AND METHODS}

The research design was characterized by a cross sectional quantitative survey, and the research data was collected from the study participants through different techniques to achieve the stated specific objectives. Cross-sectional data was employed in which data was collected at one time to describe the selected anthropometric, body composition, physical fitness and basketball skills performance of male basketball players of selected public universities in Ethiopia.

The subjects for this study were selected from the Ethiopian public university basketball competitors of the year 2016-2017 by using a multistage sampling technique. There are a total of 34 public universities in Ethiopia, where each have basketball teams. In the first stage, public universities are categorized in to three strata based on the generation (year of establishment): First generation universities, second generation universities and third generation universities to make homogenous population. In the second stage, from each strata, sample universities were selected using simple random sampling technique so as to give equal chance to be selected; hence, the two stage sampling is called stratified random sampling techniques. In the meantime, by employing proportionate to size sampling technique to each strata. Based on aforementioned sampling techniques, 12 representative ultimate Ethiopian public university basketball teams ( 2 from first generation, 5 from second generation and 5 from third generation) were selected for the study so that the anthropometric, body composition, physical fitness and basketball skill performance variables measurements were taken from 200 basketball players.

The subject tested for the Anthropometric variables: weight, height, body mass index, arm length, palm length and leg length. Body composition variables: Biceps skinfold, Triceps skinfold, subscapular skinfold, supriliac, body density, percent of fat, fat weight and lean body mass. Physical fitness variables: speed (50m dash), agility (SEMO agility test), power (sergeant jump), endurance (Harvard step test), strength (hand grip dynamometer). The dependent variables (basketball skill performance) werenot directly measured but aggregation was made using principal component analysis while it is used to reduce correlated variables in to one or two variables (Jolliffe 2002). Person's product moments correlation was used to find out the relationship of selected 
anthropometric, body composition and physical fitness variables with basketball skill performance. All the obtained data from tests and measurement wear recorded, standard descriptive statistics (mean \pm standarddeviation) and person's correlation coefficient were applied, the data were analyzed by using SPSS (statistical package for social science)version 20.0 at 0.01 level statistical significant.

\section{RESULTS}

In the present study, the anthropometric variables of Ethiopian inter university basketball players with basketball performance are described in table. The mean values and standard deviation of anthropometric variables was observed that mean age of basketball player male students in selected Ethiopian universities basketball players was 22.22 years with standard deviation of 1.88 years. Their mean, weight was $68.34 \mathrm{~kg}$ and standard deviation $10.99 \mathrm{~kg}$, and their average height was $1.80 \mathrm{~m}$ with standard deviation of $0.92 \mathrm{~m}$. In addition their average value of body mass index was $20.74 \mathrm{~kg} / \mathrm{m}^{2}$ with standard deviation of $1.27 \mathrm{~kg} / \mathrm{m}^{2}$ mean of their arm length was $84.92 \mathrm{~cm}$ with standard deviation of $6.83 \mathrm{~cm}$, Their Palme length was on average $19.67 \mathrm{~cm}$ with standard deviation of $1.55 \mathrm{~cm}$ lastly average mean leg length of male basketball players was $101.13 \mathrm{~cm}$ With standard deviation of $9.71 \mathrm{~cm}$.

It revealed that basketball skill performance was significantly and positively related to weight, height, body mass index, arm length, Palme length and leg length. $(\mathrm{r}=0.93,0.92,0.88,0.68,0.82$, 0.33 respectively). This justifies that weight, height, body mass index and Palme length were strongly related to basketball skill performance. Whereas arm length was moderately and leg length weakly related to basketball skill performance as described by Cohen (1989).

Table 1. Mean, standard deviation, correlations value between dependent and independent

\begin{tabular}{|l|c|c|c|}
\multicolumn{5}{c}{ Variables } \\
\hline Anthropometric variables & Mean & SD & Correlation (r) \\
\hline Basketball performance & 80.56 & 10.44 & \\
\hline weight & 68.34 & 10.996 & $0.93^{* *}$ \\
\hline Height & 1.80 & 0.95 & $0.92^{* *}$ \\
\hline Body mass Index & 20.74 & 1.279 & $0.88^{* *}$ \\
\hline Arm Length & 84.92 & 6.83 & $0.68^{* *}$ \\
\hline Palme Length & 19.67 & 1.55 & $0.82^{* *}$ \\
\hline Leg length & 101.13 & 9.71 & $0.33^{*}$ \\
\hline
\end{tabular}

$\mathbf{N}=200 ; \quad * *$ Significant at.0.01, *Significant at.0.05 Level of significance

The Body composition variables in relation with basketball performance are described in table -2 and it showed that body density of Ethiopian university basketball players was mean 1.07, standard deviation 0.006 , minimum and maximum values were 1.05 and 1.08 respectively. The mean value of percent of body fat was 12.32 , standard deviation was 2.75 , minimum and maximum values were 6.8 and 19.97 respectively. Besides average value of their fat weight was 8.13 , standard deviation was 0.62 minimum and maximum values were 5.85 and 9.55 respectively. Average value of lean body mass was 60.21 , standard deviation was 11.53 . Minimum and maximum values were 36.01 and 97.39 respectively.

The evident that biceps skin fold $(\mathrm{r}=-0.83)$, triceps skin fold $(\mathrm{r}=-0.81)$, subscapular skin fold $(\mathrm{r}=$ - 0.80), suprailiac skin fold $(r=-0.79)$ Percent of body fat $(r=-0.98)$, and fat weight $(r=-0.88)$ were negatively and strongly correlated with basketball skill performance at 0.01 significance level. Body density $(r=0.98)$ and lean body mass $(r=0.94)$ were positively and strongly correlated with basketball skill performance at 0.01 significance level as described by Cohen (1989). 
Table 2. Mean, standard deviation, correlations value between dependent and independent Variables

\begin{tabular}{|l|c|c|c|}
\hline Body composition variables & Mean & SD & Correlation (r) \\
\hline Basketball performance & 80.56 & 10.44 & \\
\hline Biceps skin fold & 4.27 & 1.63 & $-0.83^{* *}$ \\
\hline Triceps skin fold & 6.35 & 2.15 & $-0.81^{* *}$ \\
\hline Subscapular skin fold & 8.52 & 2.17 & $-0.80^{* *}$ \\
\hline Suprailiac skin fold & 10.59 & 2.67 & $-0.79^{* *}$ \\
\hline Body density & 1.07 & .006 & $0.98^{* *}$ \\
\hline Percent of body fat & 12.32 & 2.75 & $-0.98^{* *}$ \\
\hline Fat weight & 8.13 & .62 & $-0.88^{* *}$ \\
\hline Lean body mass & 60.21 & 11.53 & $0.94^{* *}$ \\
\hline
\end{tabular}

$\mathrm{N}=200 ; * *$ Significant at.0.01 Level

The descriptive data of the various physical fitness variables of university basketball players is shown in table -3 . The average time in $50 \mathrm{~m}$ dash (speed) of the players was 7.47 seconds with standard deviation of 0.78 . The mean SEMO agility test of the players was 10.98 seconds, whereas, the standard deviation was 1.04. The average distance in sit and reach test (flexibility) of the players was $37.24 \mathrm{~cm}$ with 2.85 of standard deviation. The basketball players had $60.24 \mathrm{~cm}$ mean value in sergeant jump (power) and standard deviation 2.5. The mean time in Harvard step test (Cardo respiratory endurance) of the players, was 84.77 minutes with 2.31 of standard deviation. The mean value of Hand grip dynamometer (strength) of the players was $109.81 \mathrm{~kg}$ whereas, thestandard deviation.

The 50 meter dash speed run test $(\mathrm{r}=-0.57)$ was moderately and significantly correlated to basketball skill performance and SEMO agility test $(\mathrm{r}=-0.76)$ was strongly and negatively correlated with basketball skill performance at 0.01 significance level .Sit and reach test for flexibility $(r=0.43)$ significantly but weakly correlated with basketball skill performance. Sergeant jump for explosive power $(r=0.78)$ was positively and significantly correlated with basketball skill performance., Harvard step test for endurance (0.67) and hand grip dynamometer for strength (0.65) were positively and moderately correlated at 0.01 level with basketball skill performance According to Cohen (1989).

Table 3. Mean, standard deviation, correlations value between dependent and independent Variables

\begin{tabular}{|l|c|c|c|}
\hline Physical fitness variables & Mean & SD & Correlation (r) \\
\hline Basketball performance & 80.56 & 10.44 & \\
\hline 50 Meter Dash speed test & 7.47 & .782 & $-0.57^{* *}$ \\
\hline SEMO Agility test & 10.98 & 1.04 & $-0.76^{* *}$ \\
\hline Sit and reach test for Flexibility & 37.24 & 2.95 & $0.43^{* *}$ \\
\hline Sergeant jump for Explosive Power & 60.24 & 2.50 & $0.78^{* *}$ \\
\hline Harvard step test for Endurance & 84.77 & 2.31 & $0.67^{* *}$ \\
\hline Hand Grip dynamometer for strength & 109.81 & 2.43 & $0.65^{* *}$ \\
\hline
\end{tabular}

$\mathbf{N}=200 ; * *$ Significant at.0.01 Level 


\section{DISCUSSION}

The finding of the present study shows that the Anthropometric variables i.e. weight, height, Arm length, Palme length and leg length have been found to possess positive and significant $(\mathrm{p}<0.01)$ correlation with basketball performance but leg length positive significant $(p<0.05)$ and week correlation with basketball performance. The result of the study was supported by Lakshya Nagar, Dharam Singh meena and Balwindar Singh (2012) he found that Anthropometric variables weight, height, Arm length, Palme length and leg lengthpositive and significant with basketball performance. Jay Kumar Pandey, Tilak Rajmeena, Inder Kerkatta and Sunita Bisht (2016)reported in their results that the significantly positive correlation with weight, height, Arm length, Palme length and leg length with basketball performance. It can be concluded from the findings of the present study that anthropometric variables contribute to selection criteria and significant in basketball performance. Body composition variables i.e. biceps skin fold, triceps skin fold, subscapular skin fold, suprailiac skin fold, body density, percent of body fat, fat weight and lean body mass are positively but significant correlated with basketball performance. This indicated that with the development of the amount of subcutaneous tissues of these muscles increase the contractile power of the muscles and hence contribute positively of basketball performance. The findings of the study are in complete agreement with the results of the earlier study reported by Sukhwinder sing (2016). The physical fitness variables was significant correlation with basketball performance. Sit reach test (flexibility), sergeant jump (power), Harvard step test (endurance), and hand grip dynamometer (strength) were having significant but positive correlation. Among these $50 \mathrm{~m}$ dash(speed) and SOME (agility test)were negative but significance correlation with basketball performance. The speed and agility are time factor, decrease the time higher the performance.Arvind Bahadur Singh (2012), Lakshya Nagar, Dharam Singh Meena and Balwindar Singh (2012) reported that physical fitness variables i.e. speed, agility, flexibility, power, endurance and strength significant relationship with basketball performance.

\section{CONCLUSION}

From the result and desiccation the following consolation have been drawn.

- There was positive and a significant relationship between the basketball performance and selected anthropometric variables such as weight, height, body mass index, arm length, palm length and leg length.

- There waspositive and a significant relationship between the basketball performance and body composition variables such as Biceps skinfold, Triceps skinfold, subscapular skinfold, suprailc skinfold, body density, percent of body fat, fat weight and lean body mass.

- Basketball performance waspositive and significantly related to speed, agility, flexibility, power, endurance and strength.

\section{ACKNOWLEGEMENT}

The Authors would like to thank all the participants of the study, basketball coaches, University management board and Debre Markos University for the financial support.

\section{REFERENCES}

Abdelkrim, N. F. (2007). Time-motion analysis and physiological data of elite under-19-year-old basketball players during competition British. Journal of Sports Medicine, 41, pp. 69-75.

Ajay Kumar Pandey, D. T. (2016, 06 12). Relationship between Selected Anthropometric Measurement and Volleyball Players Performance. International Journal of Physical Education, Sports and Health, 3(5), pp. 217-219. 


\section{Journal of Exercise Science \& Physiotherapy, Vol. 14, No. 1 (January to June), 2018 ISSN: 0973-2020 (Print) I I OR Impact Factor = 5.23 UGC Approved [no.7485] ISSN: 2454-6089 (Online)}

Angyan, L.,Teczely,T.Zalay,Z.\&Karsai,I.(2003). Relationship of anthropometrical, physiological and motor attributes to sport-specific skills. Acta Physiol. Hung. 90(3): pp 225-231.

Arvind Bahadur Singh (2012, April). relationship between playing ability and selected motor fitness variables of tribal women basketball players. International Journal of behavioral social and movement sciences, 01(02).

Astrand, P. \&. (1986). Test Book of Work.Physiology ,Physiol ogical Basis of Exercise, Ms Graw Hill Company,New York.

Bartlett, M. D. (2002, January 12). The use of performance indicators in performance analysis. Journal of Sports Sciences, pp. 739-754.

Bourgois, J. B. (2013). Morphological and Physiological Profile of Elite Basketball Players in Belgium. International Journal of Sports Physiology and Performance, 8, pp. 630-638.

Chandrasekaran2, J. V. (2011, December 9). Optimizing Position-wise Anthropometric Models for Prediction of Playing Ability among Elite Indian Basketball Players. International Journal of Sports Science and Engineering, 05, pp. 067-076.

Cohen, J. (1998). Statistical power analysis for the behavioral science (2nd ed.) ed.). Hillsdale, NJ:Lawrence Erlbaum Associates.

Dey, S.K., Kar, N. \& Debray, P. (2010). Anthropometric, motor ability and physiological profiles of Indian national club footballers: a comparative study. South African Journal for Research inSport, Physical Education and Recreation, 32 (1), 43-56.

Greene, J. J., Mcguine, T. A., Leverson, G., \& Best, T. M. (1998) Anthropometric and performance measures for high school basketball players. Journal of Athletic Training, 33(3): 229-232.

Hoffman, J.R., Epstein, S., Einbinder, M. \& Weinstein, I. (1999) the influence of aerobic capacity on anaerobic performance and recovery indices in basketball players $J$ Strength \& Conditioning Research, 13: 407-411.

Jolliffe. (2002). Principal Component Analysis. (2. edition, Ed.)

Joseph J. Greene, M. A., Timothy A. McGuine, M. A., Glen Leverson, P., \& Thomas M. Best, M. P. (1998). Anthropometric and Performance Measures for High School Basketball Players. Journal of Athletic Training, 3(33), pp. 229-232.

Lakshya Nagar2, D. S. (2012, December 18). Correlation of Selected Anthropometric and Physical Fitness Variables to Basketball. International Scientific Journal of Sport Sciences, 2(1), pp. 91-95.

McInnes, S. C. (1995). The physiological load imposed on basketball players during competition. Journal of Sports Sciences,. Journal of Sports Sciences, pp. 387-397.

Nidhal Ben Abdelkrim, S. E. (2007). Time-motion analysis and physiological data of elite under-19-year-old basketball players during competition. pp. 69-75.

Paiva, N. A. (2005). Body composition assessment in male basketball players in Brazilian National Basketball League. 7, pp. 35-44.

Singh, D. S. (2016, 02 10). Relationship between selected anthropometric variables and performance of volleyball players. International Journal of Physical Education, Sports and Health, 3(2), pp. 22-24.

Smekal, G. V. (2001). A physiological profile of tennis match play. Medicine and science in sports and exercise. 33(6), pp. 999-1005.

Conflict of Interest: None declared 